\title{
Incidence and abundance of epiphytic and epigeic lichens in response to highway traffic in Algonquin Provincial Park, Ontario
}

\author{
Scott Irving
}

This manuscript was prepared under the supervision of Professor John Fryxell, Department of Integrative Biology, College of Biological Sciences.

\begin{abstract}
Lichens are commonly used as indicator species of air pollution because of their sensitivity to prolonged exposure to sulphur dioxide, copper, zinc, arsenic, and lead from air pollution. The present study examines the incidence and abundance of lichens at varying distances from two roadways in Algonquin Provincial Park, Ontario: one with a high traffic volume, the other with a negligible traffic volume. Incidence was defined as the ratio of individuals to available habitats, while abundance was simply a count of individuals in a given space. The study found that lichen abundance did not vary significantly in relation to distance from the highway in either setting. Incidence, on the other hand, was found to increase with distance from the highway in the high-traffic site, while no such relationship was found in the low-traffic site. Obtained results suggest that incidence may be a relevant and practical measure of air quality in biomonitoring work.
\end{abstract}

$\mathrm{R}_{\mathrm{cos}}^{\mathrm{os}}$ oadways exert numerous influences over the ecological communities through which they pass. The effects of dust deposition alone on forest plants include suppression of fruit production and pollen germination, reduction in photosynthesis, and increased leaf temperature leading to increased susceptibility to drought. ${ }^{11}$ Tree removal, pollution from automobile exhaust, and road salting are linked to habitat loss and fragmentation for animals, altered species composition in roadside plants, and decreased lichen health and abundance. ${ }^{21,1}$

Lichens are of great importance to forest communities. Ecological functions of lichens include providing camouflage for the common tree-frog (Hyla versicolor), nest-building material for at least 45 species of North American birds including the ruby-throated hummingbird (Archilochus colubris), and over half the winter diet of caribou (Rangifer tarandus). ${ }^{17}$ Lichens represent a rare source of readily digestible food at all times of year and in diverse environments due to their ability to survive desiccation and sub-freezing temperatures. More generally, lichens act as pioneer species in barren or disturbed environments; their growth on rock surfaces is one of the primary stages of soil formation in such environments. 5,7

A lichen is a symbiosis between a fungus (mycobiont) and an alga or photosynthetic bacterium (photobiont); the latter secures photosynthetic energy for the former in exchange for physical protection. ${ }^{10}$ Lichens are known to easily accumulate particulate and soluble pollutants, e.g. sulphur dioxide $\left(\mathrm{SO}_{2}\right)$, copper, zinc, arsenic, and lead. ${ }^{15}$ Not having roots, lichens take up these pollutants directly from the atmosphere along with nutrients and water vapour. ${ }^{3}$ Because of their sensitivity to air pollutants, lichens are frequently used as indicator species of air quality; their abundance on trees gives a direct measure of the long-term concentration of $\mathrm{SO}_{2}$ and other pollutants in the air. ${ }^{14}$

Simply put, indicator species are endemic to environments with specific characteristics. Benthic communities have been used as indicators of salinity levels in water, ${ }^{9}$ hydrophytic vegetation may be used to indicate the boundaries of protected wetlands with seasonal water table variation, ${ }^{20}$ and copper-tolerant plants can clearly delineate economically important deposits of copper in south-central Africa. Most studies employing lichens as indicator species of air pollution have been conducted in urban and industrial settings. ${ }^{3,23,6}$ Relatively few studies, however, have exploited lichen's potential as an indicator of traffic-related air pollution.

This paper examines the incidence and abundance of epiphytic and epigeic lichens in two forest sites in Algonquin Provincial Park, Ontario: one that borders a well-travelled section of Ontario Provincial Highway 60 (experimental site), the other located along a service road within the Wildlife Research Station, which is not publicly accessible (control site).

Previous studies have suggested that lichen health diminishes with increasing proximity to a road. ${ }^{1}$ This relationship is likely the result of relatively high long-term concentrations of pollutants at short distances from the highway and lower concentrations farther away from it. One would therefore expect to observe a decrease in lichen 
incidence and abundance at close distances to the highway in the experimental site (high traffic volume), and no such difference in the control site (negligible traffic volume).

\section{Materials ANd Methods}

\section{Data collection}

Data was collected between 18 and 24 August 2007. The experimental site was located at a segment of Highway 60 close to kilometre 31 . In this experimental site, 12 transects were taken from the edge of the highway $100 \mathrm{~m}$ into the forest. These transects ran perpendicular to the highway and were evenly spaced along it at intervals of $25 \mathrm{~m}$. The highway was built in 1937 and currently has an average annual daily traffic (AADT) volume of 1400 vehicles $d^{-1}$ at the test site. ${ }^{2}$ The study space was limited to the forest on the north side of the highway so that the effect of prevailing winds would be consistent across all samples. The control site was located more than $1 \mathrm{~km}$ from the experimental site. Transects running perpendicular to the main service road (unpaved) were created in the Wildlife Research Station, where traffic is minimal compared to that of the highway $\left(<100\right.$ vehicles $\left.\mathrm{d}^{-1}\right)$. The control transects were similar in length and spacing to those in the experimental site. The species composition of trees and lichen was consistent between sites.

Preliminary research was conducted to determine which branches in the forest would be appropriate for sampling, i.e. which branches were potential sites for lichen growth. Based on this research, sampling was limited to dead branches (i.e. those with no green leaves) a minimum of $14 \mathrm{~mm}$ in diameter on balsam fir (Albies balsamea), black spruce (Picea mariana), white spruce (Picea glauca), white pine (Pinus strobus), and red pine (Pinus resinosa) trees. Only trees that fell within one arm-length $(1.0 \mathrm{~m})$ of the transect line were sampled. Each sample tree was systematically selected such that the northernmost reachable branch closest to breast height $(1.4 \mathrm{~m})$ met the above criteria for being a suitable lichen habitat.

All lichen specimens belonging to the old man's beard family (Usneaceae) was removed from each sample branch and was recorded in terms of its distance from the highway. Removal and weighing of this particular family of fruticose lichens is simple compared to other types of lichens; it was found that the true mass of foliose lichens was especially difficult to determine because of the difficulty in separating it from the bark. ${ }^{10}$ Moreover, the morphology of Usneaceae lent itself to the purposes of this study in that its structure is attached to the tree only at a single point of fixation, thereby exposing the entire organism to the surrounding atmosphere. ${ }^{16}$

The length of each sample branch was measured along the main axis. A reading of canopy cover (potentially an important confounding factor for these photosynthetic organisms) was taken at the base of each sample tree on the northern side using a densiometer. The length of each branch and the dry mass of all old man's beard collected from it were used to calculate lichen abundance in grams per metre of branch $\left(\mathrm{g} \mathrm{m}^{-1}\right)$.

\section{Epigeic lichen data}

In order to measure differences in lichen abundance over short distances, epigeic lichens were sampled in the treeless band approximately $20 \mathrm{~m}$ in width between the edge of Highway 60 and the edge of the forest (i.e. an unsuitable environment for epiphytic lichens).

The percent ground cover of fruticose epigeic lichens was sampled using a $0.5 \mathrm{H} 0.5 \mathrm{~m}$ quadrat. Ground cover estimates were taken at 2-m intervals over 21 transects which spanned the width of the treeless area. This study site contained numerous cup-like, club-like, and shrub-like lichen species, including British soldiers (Cladonia cristatella), false pixie-cup ( $C$. chlorophaea), perforated cladonia $(C$. multiformis), coral lichen (Cladina stellaris), reindeer lichen (C. rangiferina), and woolly foam lichen (Stereocaulon tomentosum). Incidence of epigeic lichens was not considered because individuals of these species are difficult to distinguish without causing damage to them.

No appropriate control site could be found within the Wildlife Research Station to measure epigeic lichen abundance in a low-traffic setting. The thick grasses and shrubs located between the road and the forest created an environment that was inhospitable for epigeic lichens.

\section{Statistical methods}

Lichens are known to have a patchy spatial distribution, i.e. the probability of encountering an individual at any point in

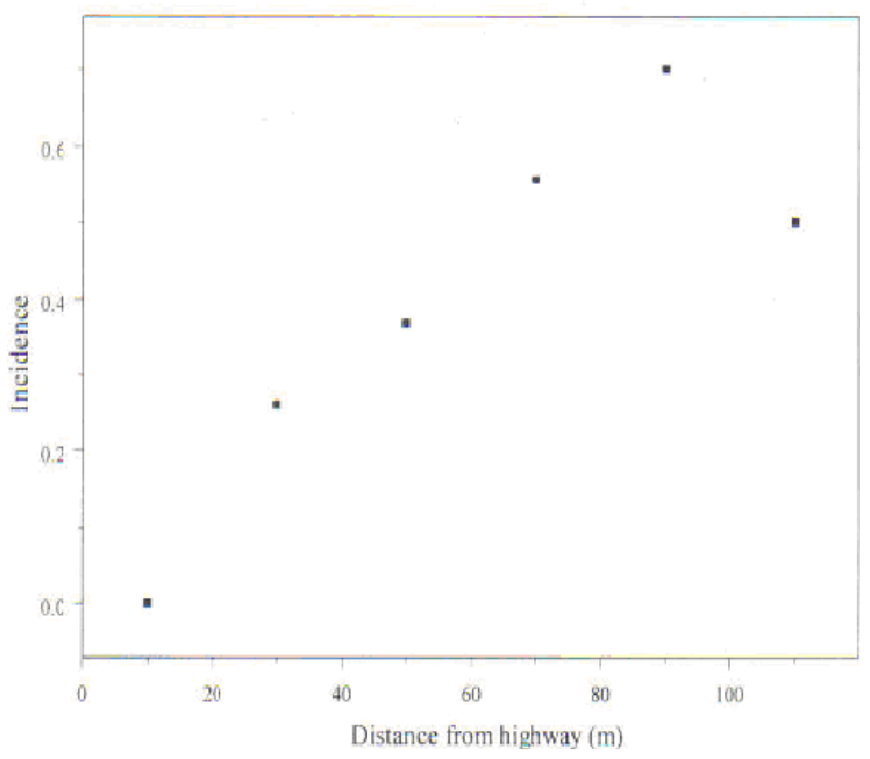

Figure 1: Epiphytic lichen incidence in the experimental site. $\mathrm{m}=0.00057, \mathrm{~b}=\mathbf{0 . 5 3 8}, \mathrm{p}=\mathbf{0 . 0 2 5 1}, \mathrm{df}=1.4$ 


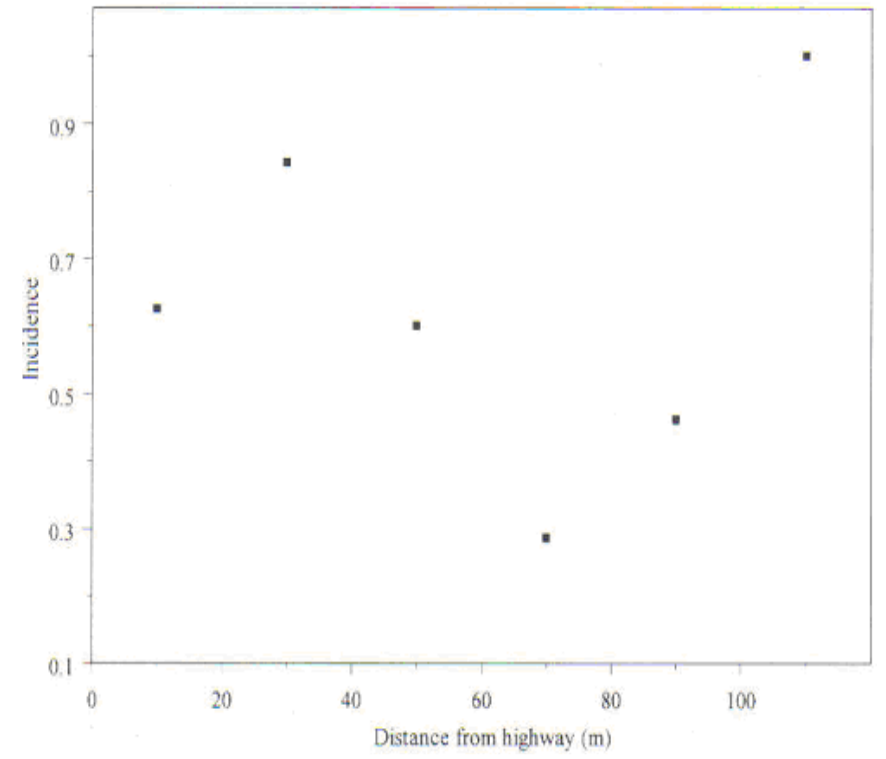

Figure 2: Epiphytic lichen incidence in the control site. $\mathrm{p}=\mathbf{0 . 8 6 9 5}, \mathrm{df}=1.4$

space is non-random. ${ }^{4,12}$ It is common practice in such rarely occurring organisms to analyse counts of the organism in terms of abundance-when-present rather than simple abundance. $^{22}$ This is done by omitting from calculations any samples that contain zero individuals so that only the relevant instances are considered.

Abundance-when-present of epiphytic old man's beard was plotted against the measured distance from the highway. Linear regressions were performed to determine the degree to which abundance-when-present varied as a function of distance in both the experimental and control data sets. Abundance-when-present was then plotted against canopy cover to discern whether variability in abundance-whenpresent was attributable to this major confounding variable as opposed to distance from the road. A two-way anova was used to detect if a particular tree species was associated with high abundance-when-present.

Epiphytic lichen incidence was calculated as the number of branches with lichen mass $>0.0000 \mathrm{~g}$ over the total number of branches with lichen mass $0.0000 \mathrm{~g}$ within each distance category $(0.0-19.9 \mathrm{~m}, 20.0-39.9 \mathrm{~m}$, etc.). In other words, the number of non-zero lichen samples was divided by the number of sampled branches (i.e. by the number of potential habitats). The incidence for each category was plotted against the middle distance of that category (i.e. 10.0 $\mathrm{m}, 30.0 \mathrm{~m}$, etc.). Regressions were performed to determine whether incidence in the experimental and control plots varied according to distance from the highway, and if so by how much.

Estimates of epigeic lichen abundance were sorted into categories of inner $(0-8 \mathrm{~m})$, intermediate $(10-16 \mathrm{~m})$, and outer $(18-22 \mathrm{~m})$ distances from the highway to observe potential small-scale road effects. The three categories were compared using a two-way anova.

\section{RESULTS}

No strong changes in abundance-when-present were observed at different distances from the highway in either the experimental or the control site, and canopy cover was not associated with any such changes either. In the experimental site the abundance-when-present had a mean of $2.2698 \forall$ $0.5834 \mathrm{~g} \mathrm{~m}^{-1}$ (range $0.0003-2.5468 \mathrm{~g} \mathrm{~m}^{-1}$ ), which did not vary significantly in relation to distance from the highway $(P=0.4105$, df $=1,41)$ or canopy cover $(P=0.4845$, $\mathrm{df}=1,41)$. The mean of abundance-when-present in the control plot was $0.2675 \forall 0.4276 \mathrm{~g} \mathrm{~m}^{-1}$ (range 0.0010 $\left.1.8462 \mathrm{~g} \mathrm{~m}^{-1}\right)$. Abundance-when-present did not vary significantly in relation to distance from the highway $(P=$ 0.1222 , df $=1,35)$ or canopy cover $(P=0.0693$, df $=1,35)$. Lichen abundance-when-present did not vary according to tree species for either the experimental $(\mathrm{df}=39)$ or the control $(\mathrm{df}=33)$ data.

The overall lichen incidence for the control site $(0.64, n=58)$ was greater than that of the experimental site $(0.45, n=96)$. A strongly positive relationship between lichen incidence and distance from a highway was observed in the experimental site. The formula of this line is $y=$ $0.0057 x+0.0538(P=0.0251, \mathrm{df}=1,4)$ (Figure 1). This was not the case in the control site; no significant linear relationship was observed ( $p=0.8695, \mathrm{df}=1,4)$ (Figure 2).

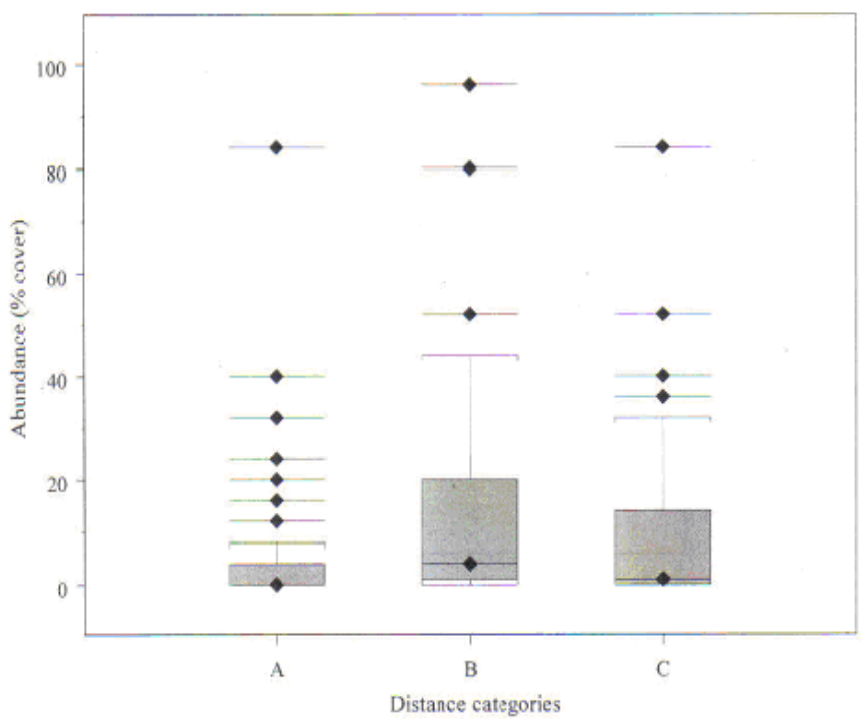

Figure 3: Epigeic lichen abundance at three small-scale distance categories: $A, 0-8 \mathrm{~m} ; \mathrm{B}, \mathbf{1 0 - 1 6 \mathrm { m }} ; \mathrm{C}, \mathbf{1 8 - 2 2 \mathrm { m }}$. Two way ANOVA indicated no significant differences ( $d f=168$ ). 
The mean percent surface area occupied by epigeic lichens in the small-scale site varied slightly among the inner ( $5 \forall 13$ $\%)$, intermediate $(13 \forall 21 \%)$, and outer $(12 \forall 20 \%)$ distance categories, but not significantly so $(\mathrm{df}=168)$ (Figure 3).

\section{DISCUSSION}

The small-scale data does not suggest that an effect on abundance is observable between the highway and the forest. The mean abundance in the intermediate distance category was the highest of the three; this was likely due to the presence of a ditch in several of the small-scale transects. The elevated levels of moisture that one would expect to find in a ditch would presumably result in a high abundance of moss, which is one of the most suitable substrates for the epigeic lichens. ${ }^{18}$ The effect of road salting was not examined, but may have overshadowed subtler pollutionrelated variation in lichen abundance.

The obtained large-scale data (i.e. the epiphytic forest lichens) is not consistent with the hypothesis that higher levels of traffic affect lichen abundance more strongly than do lower levels of traffic. If air pollution from Highway 60 does affect lichen abundance, the results were observed because this effect was consistent throughout the study area (105 m maximum from the highway) and the transects would have to have been much longer ( $500 \mathrm{~m}$, for example) in order to observe a significant difference in lichen abundance. A more likely explanation is that the effect of automobilegenerated air pollution at this traffic volume is too weak to be observed at all.

Although Highway 60 is well-travelled in relation to more isolated roadways within the park, it is far less travelled than other roadways in Ontario such as Highway 401, which reports an AADT volume of 420800 vehicles $\mathrm{d}^{-1}$ in Toronto. Future studies of lichen abundance in forests adjacent to extremely high-traffic roadways could prove to be revelatory.

A number of studies indicate that a diminished lichen abundance is strongly associated with Sulphur dioxide $\left(\mathrm{SO}_{2}\right)$ released from factories. ${ }^{8,} 16,17 \mathrm{SO}_{2}$ is also a component of automobile exhaust ${ }^{1}$ and is emitted by vehicles travelling on the highway, and yet no relationship between lichen abundance and distance from the highway was observed. A possible explanation for this is that the concentration of $\mathrm{SO}_{2}$ in automobile exhaust is much lower than that emitted from factories.

Interestingly, the data is consistent with the hypothesis that higher traffic levels exert a stronger influence over the incidence of lichens than do lower traffic levels. On average, lichen incidence in the experimental site increased by $5.7 \%$ for every ten metre increment farther from the highway. This strong positive relationship in the experimental site and the absence of any relationship at all in the control site suggests that the conditions necessary for the germination of new lichens are quite different between the two sites, germination being favoured in the unpolluted control site. Alternatively, this disparity suggests that lichens can in fact germinate and establish, but that deposition of heavy metals over the lichen's lifetime reaches toxic levels more quickly in the experimental site causing established lichens to die more frequently.

However, the observations are not consistent with this second explanation; almost no dead lichen specimens were found on branches in the transects. It seems plausible, therefore, that it is during the germination stage rather than the adult stage that lichen incidence is reduced. One possible mechanism may be traced to the bark on the branches. Tree bark is porous and practically inert due to the absence of metabolic activity in its tissue..$^{19}$ It is sometimes used as an alternative to lichens as a biomonitor because of its own tendency to accumulate heavy metals and soluble pollutants, the latter of which undergo chemical change within the bark. ${ }^{4}$ Nitrogen dioxide $\left(\mathrm{NO}_{2}\right)$, for example, acidifies branches by becoming nitrous acid $\left(\mathrm{HNO}_{2}\right)$, which stays in the bark and lowers its $\mathrm{pH} .{ }^{13}$ Lichen reproduction occurs when a fungal spore makes contact with photobiont cells living on the substrate (sexual) or when a fragment from a developed lichen containing both mycobiont and photobiont cells breaks off and begins to grow on a new substrate (asexual). ${ }^{16}$ Acidified tree bark might prove to be inhospitable for the photobiont cells, thereby inhibiting sexual reproduction. This could also prevent a lichen fragment from developing mycorrhizae, thereby inhibiting asexual reproduction. The health of other fungal organisms would be implicated under such a scenario. Future related field studies could examine $\mathrm{pH}$ levels in tree bark along highways to determine critical values for the presence of lichens and other epiphytic organisms (e.g. moss, mushrooms, etc.). Laboratory experiments could also investigate the role of acidity in cell division during lichen germination and fragmentation.

From these results, the primary objective of this study is to inform and contribute to the greater knowledge pool of biomonitoring practices and other studies dealing with indicator species. Incidence of epiphytic lichens is much more easily measured than is abundance, and even so may prove to be a more acute indicator of the levels of certain air pollutants known to be damaging to human health.

Knowledge of precisely which geographic areas have diminished lichen incidence and abundance will enable wildlife management workers to prevent the detrimental effects of toxic bioaccumulation, for example, by excluding caribou from areas containing lichens that are known to be polluted. Advances in the use of indicator species will permit more environmentally sound economic development, as well as more informed government policies dealing with road construction and city planning practices. Informed exploitation of lichens as indicator species has great potential to improve human health and the quality of the biophysical environment upon which it ultimately depends. 


\section{REFERENCES}

1. Angold, P.G. 1997. The impact of a road upon adjacent heathland vegetation: effects on plant species composition. J. Appl. Ecol. 34: 409-417.

2. Anonymous. 2005. Ontario provincial highways traffic volumes on demand [Internet]. Toronto: Queen's Printer for Ontario; [cited 2007 Oct 4]. 1 p. (Ontario Ministry of Transportation Publications). Available from:http://www.raqsa.mto.gov.on.ca/techpubs/TrafficV olumes.nsf/tvweb.

3. Augusto, S., Catarino, F., and Branquinho, C. 2007. Interpreting the dioxin and furan profiles in the lichen Ramalina canariensis Steiner for monitoring air pollution. Sci. Total Env. 377: 114-123.

4. Berlizov, A.N., Blum, O.B., Filby, R.H., Malyuk, I.A., and Tryshyn, V.V. 2007. Testing applicability of black poplar (Populus nigra L.) bark to heavy metal air pollution monitoring in urban and industrial regions. Sci. Total Env. 372: 693-706.

5. Bråkenhielm, S. and Liu, Q. 1998. Long-term effects of clear-felling on vegetation dynamics and species diversity in a boreal pine forest. Biodiversity and Conservation, 7: 207-220.

6. Conti, M.E. and Cecchetti, G. 2001. Biological monitoring: lichens as bioindicators of air pollution assessment. Env. Pollution, 114: 471-492.

7. Cooper, R. 1953. The role of lichens in soil formation and plant succession. Ecol. 34: 805-807.

8. De Wit, T. 1976. Epiphytic lichens and air pollution in The Netherlands. 1st ed. Vaduz: Cramer. 227 p.

9. Elias, R. and Bremec, C.S. 1994. Biomonitoring of water quality using benthic communities in Blanca Bay (Argentina). Sci. Total Env. 158: 45-49.

10. Esseen, P., Renhorn, K., and Pettersson, R.B. 1996. Epiphytic lichen biomass in managed and old-growth boreal forests: effect of branch quality. Ecol. App. 6: 228-238.

11. Farmer, A.M. 1999. The effects of dust on vegetation-a review. Env. Pollution, 79: 63-75.
12. Krebs, C.J. 1999. Ecological methodology. 2nd ed. Don Mills, Ontario: Addison Wesley. 620 p.

13. Krupa, S.V. 2003. Effects of atmospheric ammonia $\left(\mathrm{NH}_{3}\right)$ on terrestrial vegetation: a review. Env. Pollution, 124: 179-221.

14. Larsen, R.S., Bell, J.N.B., James, P.W., Chimonied, P.J., Rumsey, F.J., Tremper, A., and Purviset, O.W. 2007. Lichen and bryophyte distribution on oak in London in relation to air pollution and bark acidity. Env. Pollution, 146: 332-340.

15. Mikhailova, I.N. 2007. Populations of epiphytic lichens under stress conditions: survival strategies. Lichenologist: 39: 83-89.

16. Ozenda, P. and Clauzade, G. 1970. Les lichens: étude biologique et flore illustrée. 1st ed. Paris: Masson et Cie. 801

17. Richardson, D.H.S. and Young, C.M. 1977. Lichens and vertebrates. In Lichen ecology. 1st ed.

18. Edited by M.R.D. Seaward. New York: Academic Press. p. 121-144.

19. Roturier, S., Bäcklund, S., Sundén, M., and Bergsten, U. 2007. Influence of ground substrate on establishment of reindeer lichen after artificial dispersal. Silva Fennica, 41: 236-247.

20. Schulz, H., Popp, U.P., Huhna, G., Stärk, H.-J., and Schüürmanna, G. 1999. Sci. Total Env. 232: 49-58.

21. Tiner, R.W. 1991. The concept of a hydrophyte for wetland identification. Biosci. 41: 236-247.

22. Trombulak, S.C., and Frissel, C.A. 2000. Review of ecological effects of roads on terrestrial and aquatic communities. Conservation Biology, 14: 18-30.

23. Wright, D.H. 1991. Correlations between incidence and abundance are expected by chance. J. Biogeo. 18: 463466.

24. Yazici, K., and Aslan, A. 2006. Distribution of epiphytic lichens and air pollution in the city of Trabzon, Turkey. Bull. Environ. Contam. Toxicol. 77: 838-845. 